\title{
Nitrogen and Sulfur Self-Doped Activated Carbon Directly Derived from Elm Flower for High-Performance Supercapacitors
}

\author{
Hui Chen, ${ }^{\dagger}$ Feng Yu, ${ }^{*}{ }^{\dagger}$ Gang Wang, ${ }^{\dagger}$ Long Chen, ${ }^{\dagger}$ Bin Dai, ${ }^{\dagger}$ (i) and Shanglong Peng*,*
}

${ }^{\dagger}$ Key Laboratory for Green Processing of Chemical Engineering of Xinjiang Bingtuan, School of Chemistry and Chemical Engineering, Shihezi University, Shihezi 832003, P. R. China

${ }^{\ddagger}$ School of Physical Science and Technology, Lanzhou University, Lanzhou 730000, P. R. China

Supporting Information

ABSTRACT: N,S-Doped activated carbon was directly prepared via a facile and cost-efficient hydrothermal reaction, followed by alkali activation of elm flower (EL)-derived biomass. The EL-derived activated carbon (ELAC) had N and S contents of 2.21 and 6.06 atom \%, respectively, in addition to a high Brunauer-Emmett-Teller (BET) surface area of $2048.6 \mathrm{~m}^{2} \mathrm{~g}^{-1}$ and moderate pore volume of $0.88 \mathrm{~cm}^{3} \mathrm{~g}^{-1}$. Owing to its high BET surface area and N/S functional groups, ELAC achieved a specific capacitance of $275 \mathrm{~F} \mathrm{~g}^{-1}$ at a current density of $1 \mathrm{~A} \mathrm{~g}^{-1}$ and retained a capacitance of $216 \mathrm{~F} \mathrm{~g}^{-1}$ at $20 \mathrm{~A} \mathrm{~g}^{-1}$. In addition, a symmetric supercapacitor based on N,S-self-doped ELAC electrode provided a capacitance of $62 \mathrm{~F} \mathrm{~g}^{-1}$ at a current density of $10 \mathrm{~A} \mathrm{~g}^{-1}$, with maximum energy and power densities of $16.8 \mathrm{Wh} \mathrm{kg}^{-1}$ and $600 \mathrm{~W} \mathrm{~kg}$, respectively. The capacitance retention was also high, at $87.2 \%$, at $4 \mathrm{~A} \mathrm{~g}^{-1}$
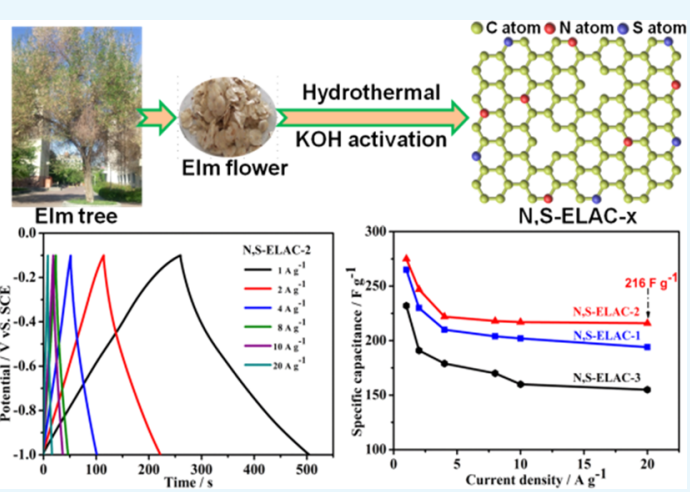
after 5000 cycles.

\section{INTRODUCTION}

With the increasing global fossil-fuel consumption and aggravating environmental pollution, alternative eco-friendly energy sources are of great importance. Supercapacitors, also known as electrochemical capacitors, are promising energystorage devices. ${ }^{1-3}$ Owing to their long lifetime and fast charge-discharge properties, supercapacitors have been extensively studied and used in experimental settings. ${ }^{4,5}$ On the basis of their energy-storage mechanism, they can be classified as either electrical double-layer capacitors (EDLCs) or pseudocapacitors. Pseudocapacitors are based on Faradic processes, whereas EDLCs are based on electrostatic charging at the electrode-electrolyte interface. Therefore, the specific surface area of its electrode significantly influences its capacitance. $^{6}$

Among various carbon materials that can be used as electrodes in supercapacitors, ${ }^{7-9}$ activated carbon is advantageous because of its high specific surface area and relatively low cost. Heteroatom doping contributes to the improvement in electrochemical performance of activated carbon by altering its electron-donor properties. Doping with nitrogen or sulfur improves capacitive performance by reducing charge transfer resistance and increasing the wettability between electrolyte and electrode, effectively enhancing electrochemical performance. $^{10-12}$ Nitrogen doping has been performed with both organic and inorganic nitrogen sources, ${ }^{13-16}$ urea, ${ }^{17,18}$ and ammonia. $^{19,20}$ In 2011, corncob-derived, nitrogen-doped activated carbon was obtained by $\mathrm{KOH}$ activation in $\mathrm{NH}_{3}$ atmosphere. ${ }^{19}$ The resulting electrode exhibited a maximum specific capacitance of $185 \mathrm{~F} \mathrm{~g}^{-1}$ in the organic electrolyte. Similarly, sulfur doping is also important in energy-storage processes. $^{21-23}$ Sulfur-doped activated carbon was obtained by directly mixing sulfur flakes with activated carbon and subsequently pyrolyzing the mixture. ${ }^{24}$ The sulfur-doped activated carbon contained many thiophene functional groups on its surface, which improve the conductivity of electrode materials. Alternatively, activated carbon can be simultaneously doped with sulfur and nitrogen. ${ }^{25,26}$ The presence of sulfur improves the pseudocapacitive performance, ${ }^{28,29}$ whereas that of nitrogen improves the electron-transfer properties of the carbon material. ${ }^{19}$ For example, willow-catkin-derived nitrogen and sulfur co-doped porous carbon nanosheets were prepared by $\mathrm{KOH}$ activation with thiourea as a precursor to both $\mathrm{N}$ and $\mathrm{S}$ atoms. ${ }^{27}$ Overall, these studies indicate that activated carbon with a high specific surface area and moderate heteroatom doping exhibits good capacitive performance.

Herein, we successfully prepared activated carbon samples derived from elm flower (EL) biomass, which were found to contain significant amounts of self-doped nitrogen and sulfur. Elm tree is a virescence tree, ubiquitous in northern China. Elm flowers mature at the end of spring and represent a cheap and accessible biomass source for activated carbon samples with high specific surface area. ${ }^{30}$ Moreover, these are usually burned or piled up casually, presenting an environmental problem.

Received: February 4, 2018

Accepted: April 23, 2018

Published: April 30, 2018 

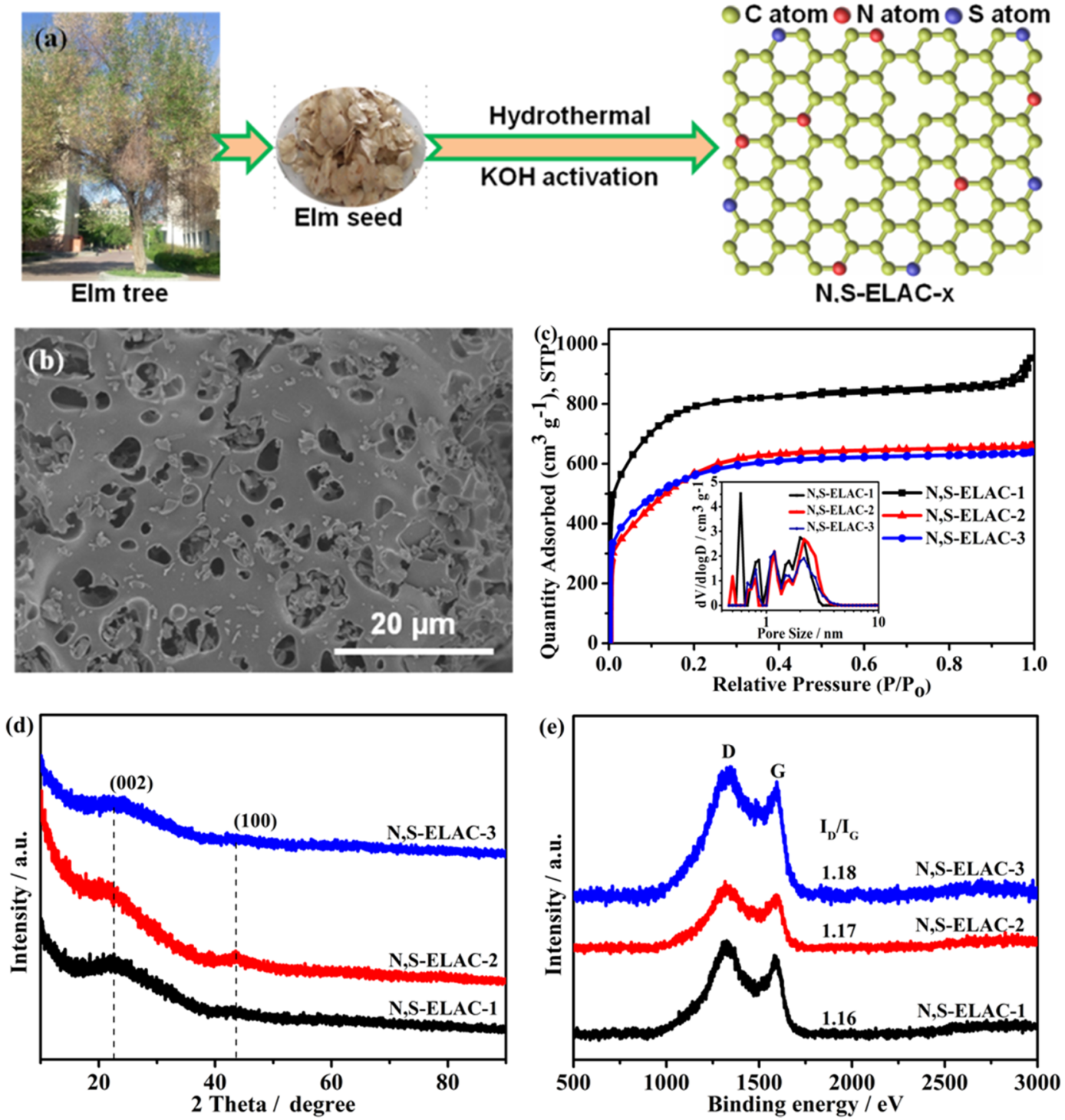

Figure 1. (a) Schematic illustration of synthesis process employed for N,S-ELAC- $x$. (b) Typical scanning electron microscopy (SEM) image of N,SELAC-2. (c) Nitrogen adsorption/desorption isotherms and inserted pore size distribution (PSD); (d) X-ray diffraction (XRD) patterns and (e) Raman spectra of the as-prepared N,S-ELAC- $x$.

Table 1. Specific Surface Area, Pore Volume, Pore Diameter, and Element Content for As-Prepared HEL and N,S-ELAC-x Samples

\begin{tabular}{|c|c|c|c|c|c|c|c|}
\hline \multirow[b]{2}{*}{ samples } & \multirow[b]{2}{*}{$S_{\mathrm{BET}}\left(\mathrm{m}^{2} \mathrm{~g}^{-1}\right)^{a}$} & \multirow[b]{2}{*}{$V_{\text {total }}\left(\mathrm{cm}^{3} \mathrm{~g}^{-1}\right)^{b}$} & \multirow[b]{2}{*}{$D_{\text {pore diameter }}(\mathrm{nm})^{c}$} & \multicolumn{4}{|c|}{ composition (atom \%) ${ }^{d}$} \\
\hline & & & & $\mathrm{C}$ & $\mathrm{O}$ & $\mathrm{N}$ & $S$ \\
\hline HEL & 6.13 & & 36 & 78.47 & 4.15 & 2.61 & 15.59 \\
\hline N,S-ELAC-1 & 2638.94 & 1.23 & 3.4 & 80.14 & 7.11 & 2.8 & 9.94 \\
\hline N,S-ELAC-2 & 2048.57 & 0.88 & 2.6 & 85.07 & 6.66 & 2.21 & 6.06 \\
\hline N,S-ELAC-3 & 1928.82 & 0.83 & 2.8 & 92.62 & 3.97 & 2.61 & 0.8 \\
\hline
\end{tabular}

${ }^{a}$ Specific surface area calculated by Brunauer-Emmett-Teller (BET) method. ${ }^{b}$ Total pore volume of as-prepared materials. ${ }^{c}$ Average pore diameter of as-prepared materials. ${ }^{d}$ Element contents analyzed by X-ray photoelectron spectroscopy (XPS).

Thus, their conversion into activated carbon offers a practical removal method. We showed that the EL-derived activated carbon (ELAC) exhibits a high specific surface area (2048.57 $\mathrm{m}^{2} \mathrm{~g}^{-1}$ ) and moderate $\mathrm{N}$ and $\mathrm{S}$ contents (2.12 and 6.06 atom $\%$, respectively). As a supercapacitor electrode material, ELAC displays good capacitive performance and decent rate capability both in three- and two-electrode systems.

\section{RESULTS AND DISCUSSION}

The preparation of nitrogen and sulfur self-doped ELAC is illustrated in Figure 1a. The biomass raw materials, EL, were collected from the ground and subjected to hydrothermal treatment and $\mathrm{KOH}$ activation. The harsh conditions of hydrothermal treatment led to the partial carbonization, hydrolysis, and partial dissolution of noncrystalline regions of the two-dimensional biomass materials. ${ }^{33}$ Furthermore, the 

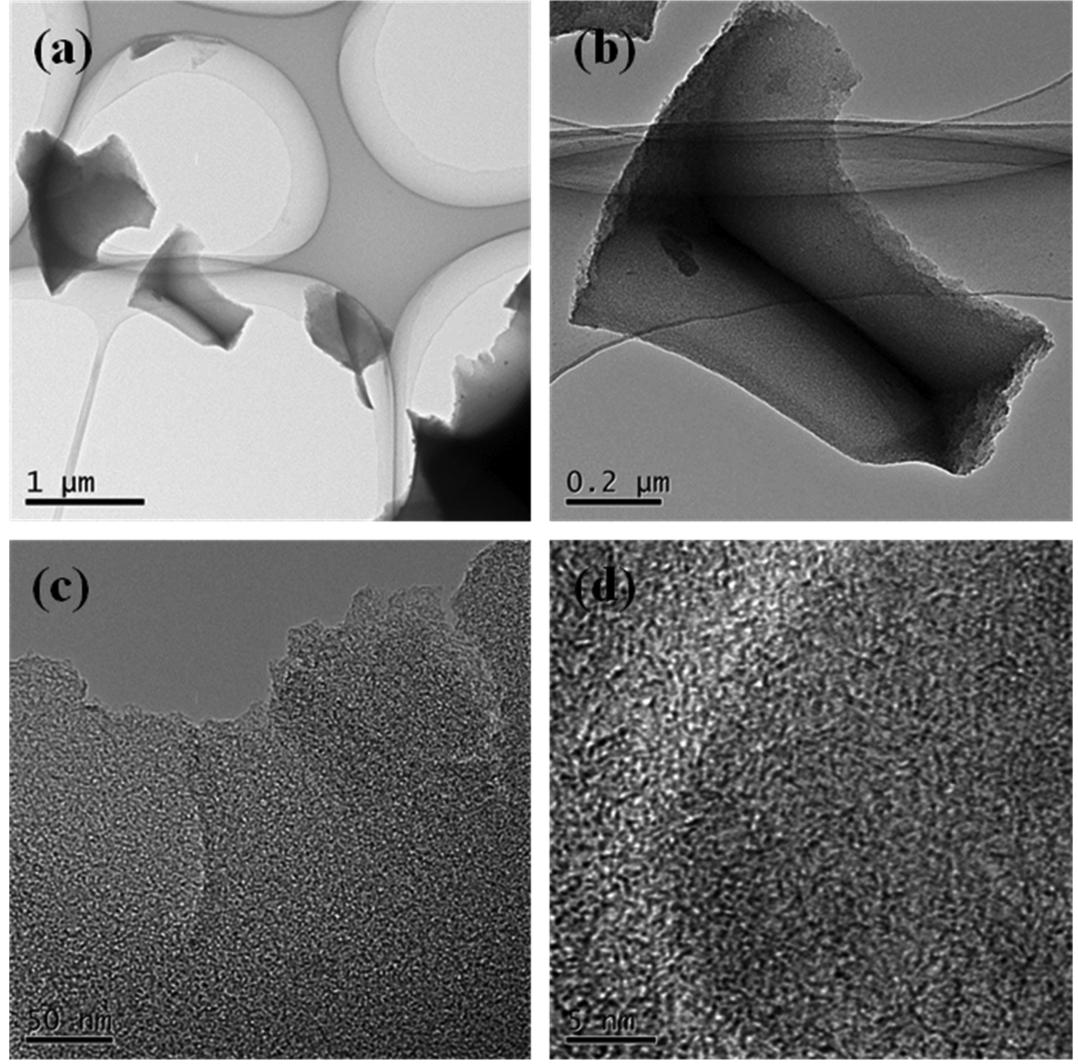

Figure 2. $(a-c)$ TEM images and (d) high-resolution TEM image of as-prepared N,S-ELAC-2.

process decreased the crystallinity and connection between microfibers of the samples. However, their elemental composition was conserved after the hydrothermal process ${ }^{34}$ and their porosity increased with the amount of $\mathrm{KOH}$ during the activation process. $\mathrm{KOH}$ activation also diminished the amount of spherical structures and increased that of porelike structures. The products were denoted by N,S-ELAC- $x$, where $x$ is the mass ratio between $\mathrm{KOH}$ and HEL. Both macro- and micropores were observed within the pore structure, indicating successful $\mathrm{KOH}$ activation of the HEL (Figure 1b).

The specific surface area and pore structures of N,S-ELAC- $x$ were further studied by nitrogen adsorption-desorption isotherm measurements. As shown in Figure 1c, N,S-ELAC-1 (KOH/HEL mass ratio 1:1) provided a typical type-IV adsorption-desorption isotherm, ${ }^{35}$ which exists as an hysteresis loop at high relative pressure. The typical type-I adsorptiondesorption isotherms obtained from increasing $\mathrm{KOH}$ mass ratios in the N,S-ELAC-2 and N,S-ELAC-3 samples suggest the presence of micropores. ${ }^{36}$ Prominent peaks in the PSD (inset in Figure 1c) are observed at 0.58, 0.86, 1.17, 1.58, and $2.1 \mathrm{~nm}$. Table 1 summarizes the Brunauer-Emmett-Teller (BET) surface area and pore structure characterization parameters of the as-prepared materials. As shown in Figure S1, the HEL mainly exhibited spherical amorphous carbon structures with small specific surface area.

$\mathrm{KOH}$ activation led to a remarkable increase in the specific surface area, from 6.13 (HEL) to $2638.9 \mathrm{~m}^{2} \mathrm{~g}^{-1}$ (N,S-ELAC-1). Although pore volume was not detected in the preactivated material (Table 1), indicating blocked pore texture, $\mathrm{KOH}$ activation resulted in a porous structure. ${ }^{37}$ The N,S-ELAC-1, N,S-ELAC-2, and N,S-ELAC-3 KOH-treated samples had total pore volumes of $1.23,0.88$, and $0.83 \mathrm{~cm}^{3} \mathrm{~g}^{-1}$, respectively. The porous structure and significantly higher specific surface area of these samples improve the accessibility of ions at high charge/ discharge rates and reduce the ion transport time from the electrolyte to electrode, which is one of the main factors necessary for satisfactory power performance. ${ }^{17,38}$ At a $\mathrm{KOH} /$ HEL ratio above unity, increasing concentrations of $\mathrm{KOH}$ decreased the specific surface area, from $2048.6 \mathrm{~m}^{2} \mathrm{~g}^{-1}$ (N,SELAC-2) to $1928.8 \mathrm{~m}^{2} \mathrm{~g}^{-1}$ (N,S-ELAC-3), as excessive quantity of $\mathrm{KOH}$ leads to pore structure collapse. ${ }^{39,40}$

$\mathrm{X}$-ray diffraction (XRD) analysis of the $\mathrm{KOH}$-activated materials (Figure 1d) revealed two broad and weak peaks at 22.3 and $43.8^{\circ}$ that can be ascribed to (002) and (100) reflections of the disordered carbon layer, respectively. ${ }^{41}$ The presence of a weak and broad (002) peak suggests the formation of a microporous structure after direct $\mathrm{KOH}$ activation. The spectrum of N,S-ELAC-2 sample exhibited a relatively sharper (100) peak, which implies a relatively higher degree of graphitization among the carbon atoms. ${ }^{41,42}$ The chemical structure and degree of disorder were also characterized by Raman spectroscopy (Figure 1e). The D band at $1337 \mathrm{~cm}^{-1}$ is attributed to structural defects and impurities, whereas the $\mathrm{G}$ band at $1594 \mathrm{~cm}^{-1}$ corresponds to inplane stretching vibrations of $\mathrm{sp}^{2}$ hybridized carbon in graphite crystallites. ${ }^{36,43}$ High-integrated intensity ratios $\left(I_{\mathrm{D}} / I_{\mathrm{G}}\right)$ for N,SELAC-1 (1.16), N,S-ELAC-2 (1.17), and N,S-ELAC-3 (1.18) were attributed to increased disorder and defect structure in the $\mathrm{KOH}$-activated carbon materials. In addition, these also indicate an increase in the content of oxygen-containing functional groups in as-prepared N,S-ELAC- $x$ samples. ${ }^{44}$

Transmission electron microscopy (TEM) images were observed to identify the porosity of the samples. As shown in Figure $2 \mathrm{a}-\mathrm{c}, \mathrm{N}, \mathrm{S}$-ELAC-2 clearly contains abundant micropore 

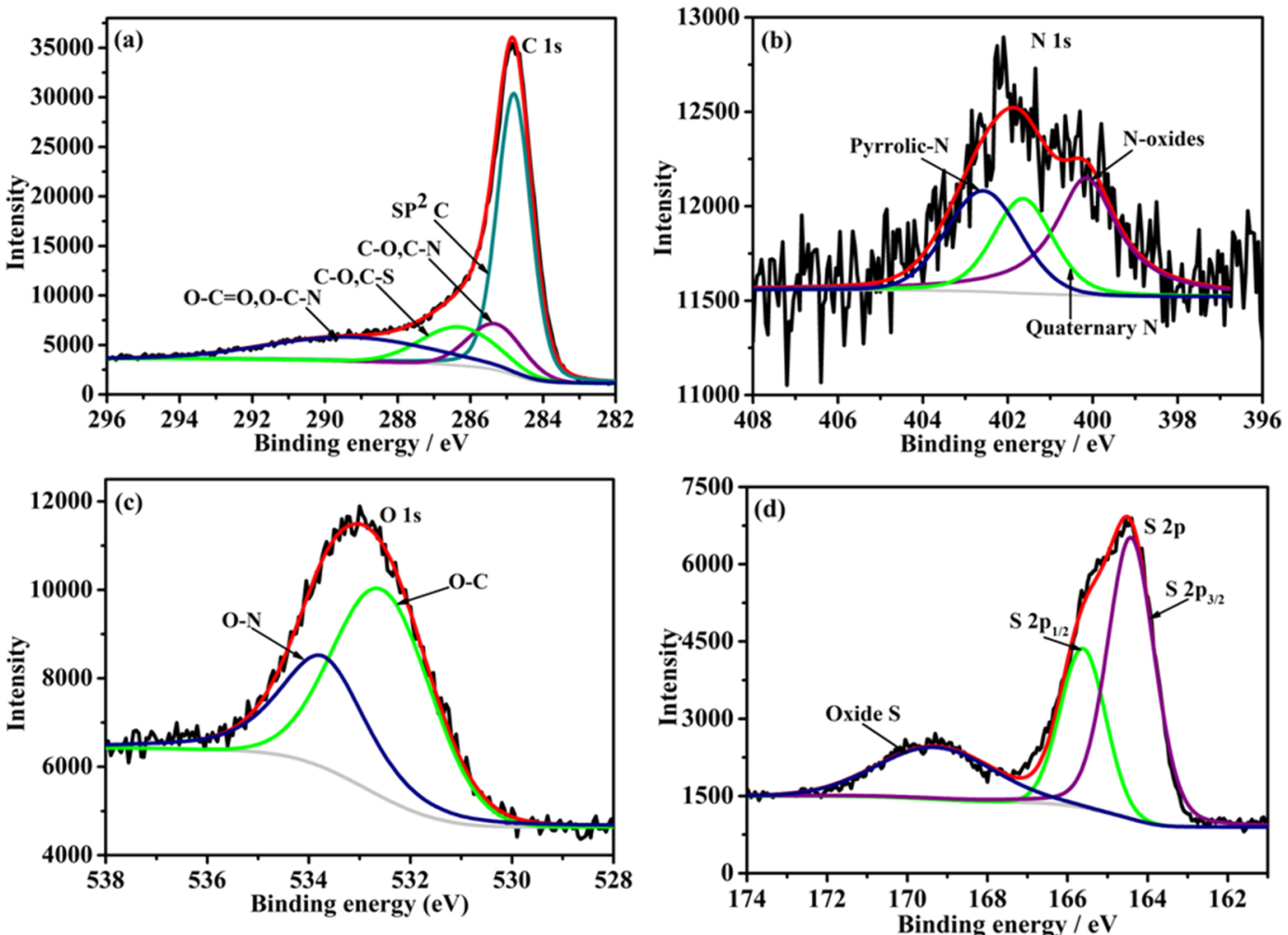

Figure 3. High-resolution (a) C 1s, (b) $\mathrm{N}$ 1s, (c) O 1s, and (d) $\mathrm{S} 2 \mathrm{p}$ spectra of the N,S-ELAC-2.
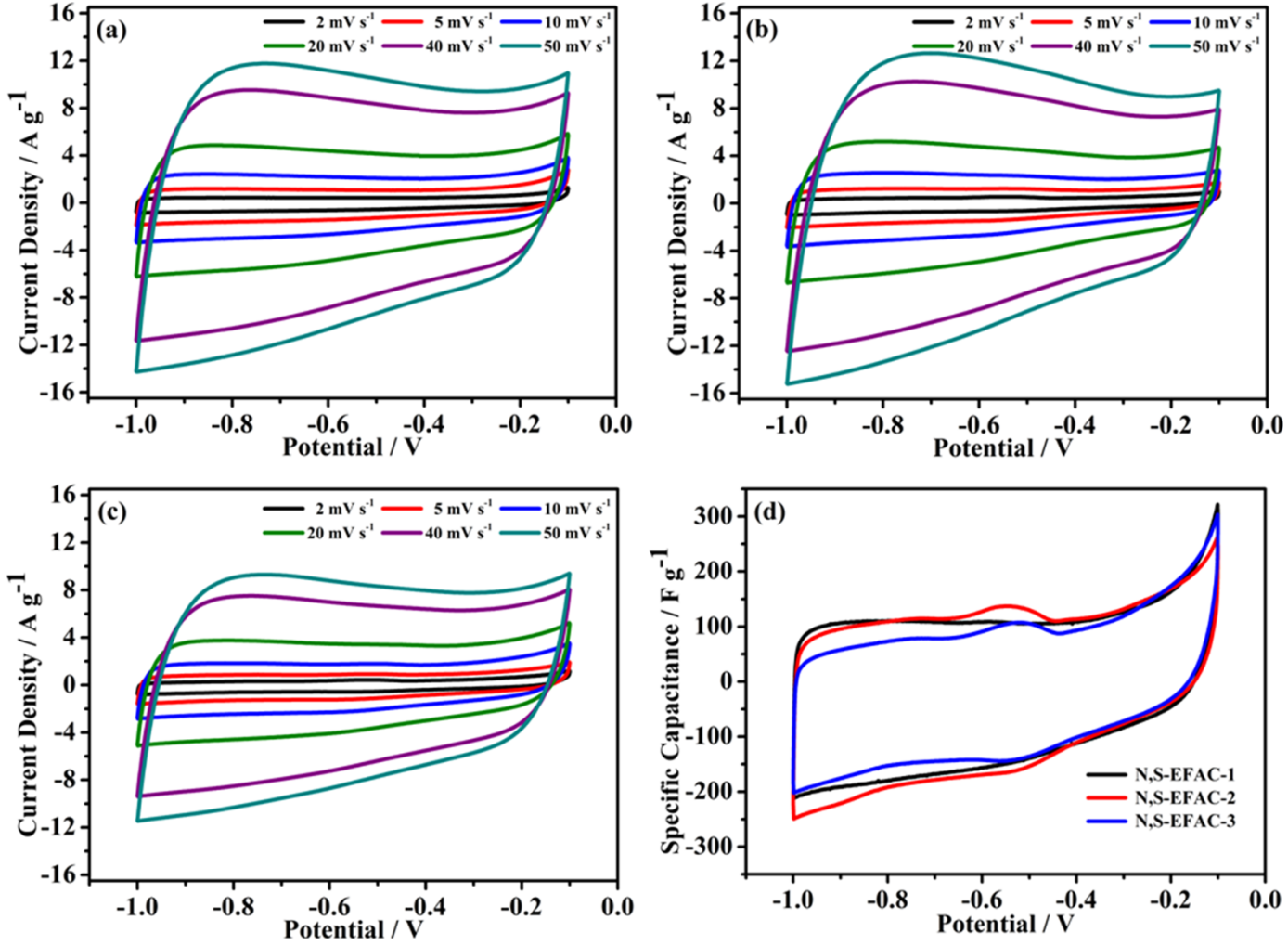

Figure 4. CV curves of (a) N,S-ELAC-1, (b) N,S-ELAC-2, and (c) N,S-ELAC-3 at different scan rates. (d) Comparison of N,S-ELAC- $x$ at the scan rate of $2 \mathrm{mV} \mathrm{s}^{-1}$.

structures, consistent with the BET results. In addition, a highresolution TEM image proved the existence of a disordered carbon structure at the edge of the material (Figure $2 \mathrm{~d}$ ). The elemental composition of the as-prepared materials was determined by X-ray photoelectron spectroscopy (XPS, Figure 3 ), which revealed $S, C, N$, and $O$ contents, as evidenced by the 

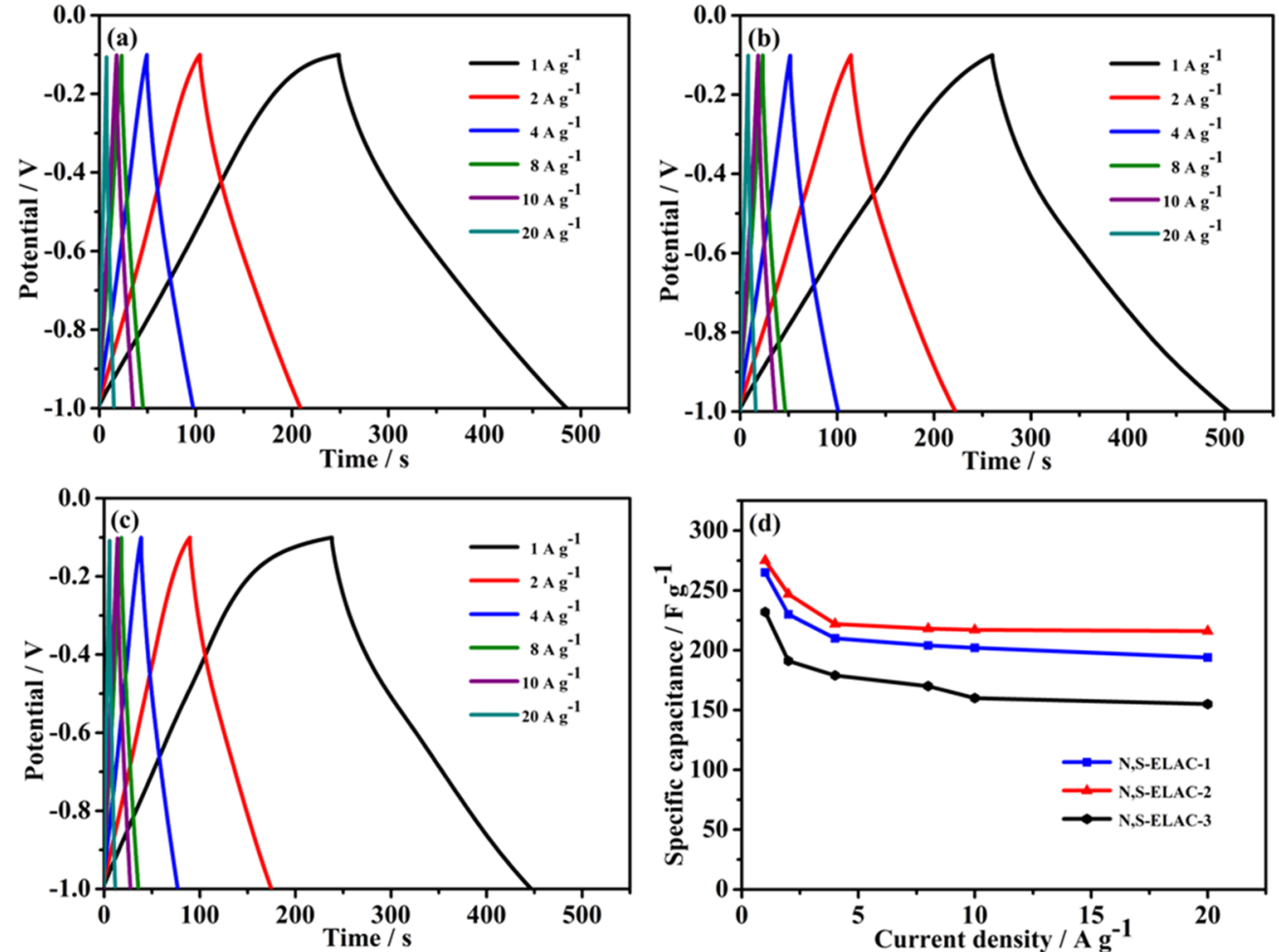

Figure 5. GCD curves of (a) N,S-ELAC-1, (b) N,S-ELAC-2, and (c) N,S-ELAC-3 at different current densities. (d) Specific capacitance of N,SELAC- $x$ calculated by GCD curves.

Table 2. Comparison of Different Nitrogen- and Sulfur-Doped Carbon for Supercapacitor Electrode Materials

\begin{tabular}{|c|c|c|c|c|c|c|c|}
\hline samples & $\begin{array}{l}\text { carbon } \\
\text { sources }\end{array}$ & $\begin{array}{l}\text { nitrogen/sulfur } \\
\text { sources }\end{array}$ & $\begin{array}{c}S_{\mathrm{BET}} \\
\left(\mathrm{m}^{2} \mathrm{~g}^{-1}\right)\end{array}$ & $\begin{array}{l}\text { capacitance } \\
\left(\mathrm{F} \mathrm{g}^{-1}\right)\end{array}$ & $\begin{array}{l}\text { measurements condition } \\
\qquad\left(\mathrm{A} \mathrm{g}^{-1}\right)\end{array}$ & electrolyte & ref \\
\hline nitrogen-doped porous carbon & potato & melamine & 1052 & 192 & 10 & $2 \mathrm{M} \mathrm{KOH}$ & 14 \\
\hline nitrogen-doped porous carbon foam & banana peel & $\mathrm{NH}_{3}$ & 1357.6 & 210.6 & 0.5 & $6 \mathrm{M} \mathrm{KOH}$ & 50 \\
\hline nitrogen-doped activated carbons & corncobs & $\mathrm{NH}_{3}$ & 2859 & 185 & 0.4 & Organic & 19 \\
\hline $\mathrm{N}$-doped porous carbon & cotton & melamine & 617 & 360 & 0.5 & $6 \mathrm{M} \mathrm{KOH}$ & 51 \\
\hline $\begin{array}{l}\text { sulfur-doped hierarchically porous } \\
\text { carbon }\end{array}$ & glucose & thiourea & 735 & 252 & 4.0 & $1 \mathrm{M} \mathrm{H}_{2} \mathrm{SO}_{4}$ & 23 \\
\hline $\begin{array}{l}\text { sulfur-doped nanoporous carbon } \\
\text { sphere }\end{array}$ & glucose & sulfur & 3357 & 405 & 0.5 & $6 \mathrm{M} \mathrm{KOH}$ & 21 \\
\hline N,S-doped activated carbon & $\begin{array}{l}\text { willow } \\
\text { catkin }\end{array}$ & thiourea & 1533 & 298 & 0.5 & $6 \mathrm{M} \mathrm{KOH}$ & 27 \\
\hline $\mathrm{N}, \mathrm{S}$-doped activated carbon & elm flower & & 2048.6 & 216 & 20 & $6 \mathrm{M} \mathrm{KOH}$ & this work \\
\hline
\end{tabular}

presence of peaks at $165,284,400$, and $532 \mathrm{eV}$, respectively. HEL had a high $S$ content (15.59 atom \%) and a moderate $\mathrm{N}$ content (2.61 atom \%) (Table 1). After $\mathrm{KOH}$ activation, the HEL exhibited an average $S$ content of 6.06 atom \% with no significant change in the $\mathrm{N}$ content. On the basis of these findings, we expect that N,S-ELAC-2 will have optimum capacitive properties.

The high-resolution $\mathrm{C} 1 \mathrm{~s}, \mathrm{~N} 1 \mathrm{~s}, \mathrm{O} 1 \mathrm{~s}$, and $\mathrm{S} 2 \mathrm{p}$ spectra of N,S-ELAC-2 are shown in Figure 3. The C 1s spectrum (Figure 3a) can be deconvoluted into four peaks centered at 284.8 (52.49\%), 285.3 (12.82\%), 286.3 (14.88\%), and $289.3 \mathrm{eV}$ (19.78\%), assigned to $\mathrm{sp}^{2}-\mathrm{C}$ hybridized $\mathrm{C}=\mathrm{C}$ bonds, $\mathrm{C}-\mathrm{O} /$ $\mathrm{C}-\mathrm{N}$ bonds, $\mathrm{C}-\mathrm{O} / \mathrm{C}-\mathrm{S}$ bonds, and $\mathrm{O}-\mathrm{C}=\mathrm{C} / \mathrm{O}-\mathrm{C}-\mathrm{N}$ bonds, ${ }^{45,46}$ respectively. The deconvoluted $\mathrm{N} 1 \mathrm{~s}$ spectrum (Figure 3b) presented peaks at 398.5 (3.5\%), 400.0 (43.25\%), $401.4(44.7 \%)$, and $403(37.8 \%) \mathrm{eV}$, corresponding to pyridinic, pyrrolic, quaternary $\mathrm{N}$ atoms, and $\mathrm{N}$ oxides, respectively. ${ }^{47}$ The presence of pyridinic, pyrrolic, quaternary $\mathrm{N}$ atoms, and $\mathrm{N}$ oxides promotes the ion transport from the electrolyte to electrode material, effectively enhancing the capacitive properties. Quaternary $\mathrm{N}$ atoms and $\mathrm{N}$ oxides also increase the capacitance of electrode materials. ${ }^{31}$ The $\mathrm{O} 1 \mathrm{~s}$ spectrum can be deconvoluted (Figure 3c) into two peaks at $532(32.17 \%)$ and $533.4(67.83 \%) \mathrm{eV}$, corresponding to $\mathrm{O}-\mathrm{C}$ and $\mathrm{O}-\mathrm{N}$ bonds, respectively. ${ }^{38}$ For the $\mathrm{S} 2 \mathrm{p}$ spectrum (Figure $3 \mathrm{~d})$, three peaks at 164.4 (52.16\%), 165.6 (26.08\%), and 169.3 (21.75\%) eV were observed upon deconvolution, corresponding to $S 2 p_{3 / 2}, S 2 p_{1 / 2}$, and oxidized sulfur, respectively. The dominant $S 2 p_{3 / 2}$ and $S 2 p_{1 / 2}$ peaks result from the spin-orbit coupling between thiophene sulfur atoms. The presence of sulfur atoms can also enhance energy storage by increasing the pseudocapacitance of the electrode. ${ }^{24}$

The electrochemical performance of N,S-ELAC- $x$ as a supercapacitor electrode material was first tested in a threeelectrode system and evaluated by cyclic voltammetry (CV) and galvanostatic charge-discharge (GCD) measurements. The CV curves of activated N,S-ELAC- $x$ were measured at the scan rates ranging from 2 to $50 \mathrm{mV} \mathrm{s}^{-1}$ in $6 \mathrm{M} \mathrm{KOH}$ electrolyte 

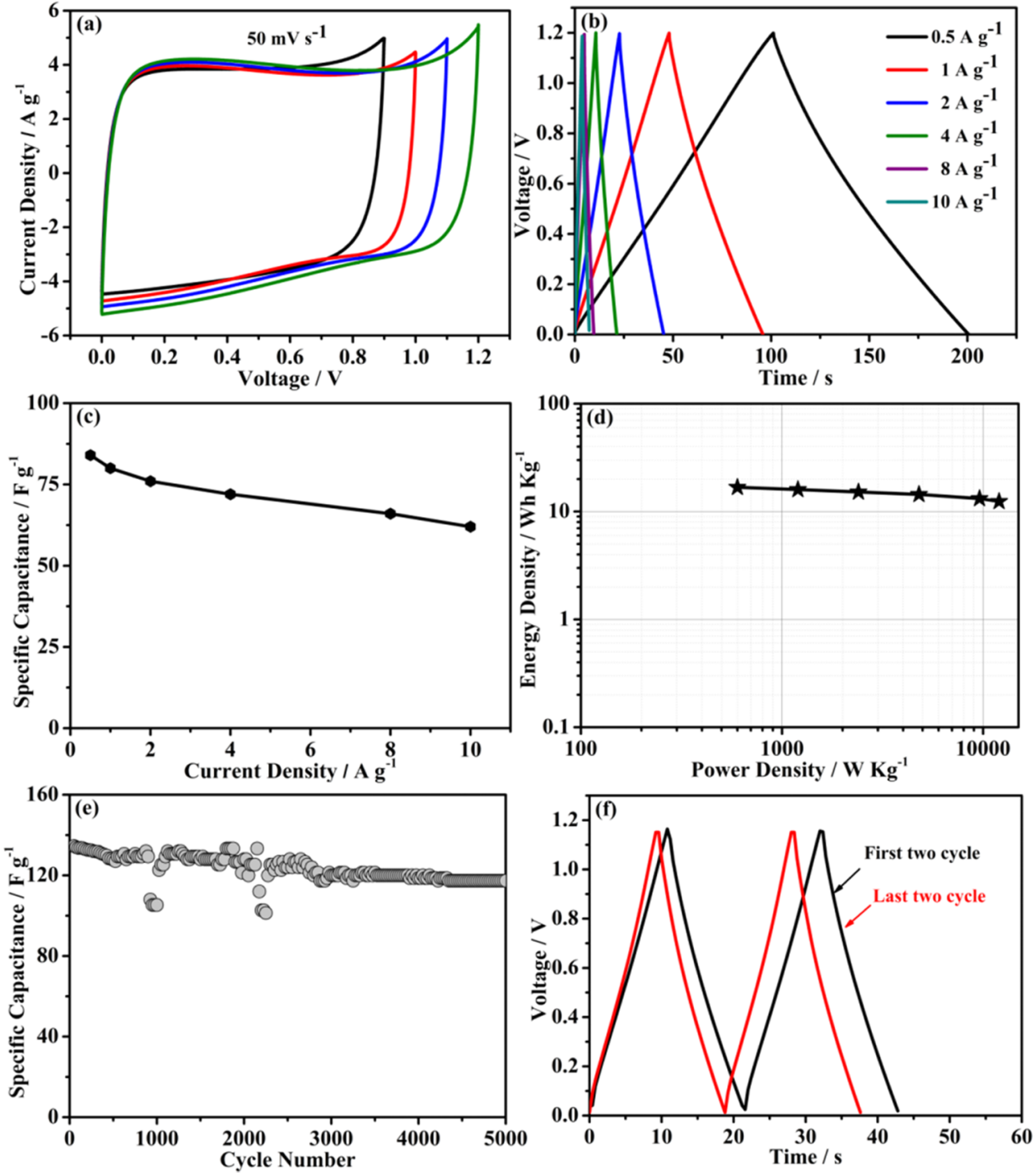

Figure 6. (a) CV curves of symmetrical supercapacitor in different operation potentials. (b) Charge-discharge curves at different current densities. (c) The specific capacitance values at different current densities. (d) Ragone plot of the symmetric cell. (e) Long-cycle stabilities at current density of $4 \mathrm{~A} \mathrm{~g}^{-1}$. (f) The charge-discharge curves of first two cycles and last two cycles in the 5000 cycle life test.

(Figure $4 a-c)$. The rectangular voltammetry curve over a potential window of -1 to $-0.1 \mathrm{~V}$ indicated that the electrochemical behavior corresponds to that of a typical electrical double-layer capacitor (EDLC) created at the electrode-electrolyte interface. The curves for the three $\mathrm{KOH}$-activated materials are shown in Figure 4d. At $2 \mathrm{mV}$ $\mathrm{s}^{-1}$, N,S-ELAC-2 exhibited higher current density responses and higher specific capacitances. Moreover, the redox peaks were related to several of heteroatom-containing functional groups in the as-prepared materials. ${ }^{48}$

The GCD curves of the KOH-activated N,S-ELAC- $x$ samples tested at six different current densities ranging from 1 to $20 \mathrm{~A}$ $\mathrm{g}^{-1}$ are shown in Figure $5 \mathrm{a}-\mathrm{c}$. These exhibited relatively good linearity and had a nearly symmetrical triangular shape, suggesting charge storage via double-layer mechanism. The higher discharge time of N,S-ELAC-2 compared to that of either N,S-ELAC-1 or N,S-ELAC-3 indicates that N,S-ELAC-2 has a relatively higher specific capacitance. Columbic efficiency was also calculated on the basis of the ratio of discharge/charge time. ${ }^{52-54}$ As shown in Figure S2, the as-obtained N,S-ELAC- $x$ samples displayed higher efficiency. The specific capacitance of the three $\mathrm{KOH}$-activated samples (calculated using eq 1 ) at six current densities ranging from 1 to $20 \mathrm{~A} \mathrm{~g}^{-1}$ is illustrated in Figure 5d. At $1 \mathrm{~A} \mathrm{~g}^{-1}$, N,S-ELAC-2 provided a capacitance of $275 \mathrm{~F} \mathrm{~g}^{-1}$. Furthermore, at $20 \mathrm{~A} \mathrm{~g}^{-1}$, a maximum specific capacitance of $216 \mathrm{~F} \mathrm{~g}^{-1}$ was retained, suggesting excellent rate performance with $78.5 \%$ capacity retention (Figure $5 \mathrm{~d}$ ).

The electrochemical properties of other heteroatom-doped carbon materials are shown in Table 2, which include those derived from willow catkin, ${ }^{27}$ bamboo, ${ }^{49}$ corncobs, ${ }^{19}$ banana peels, $^{50}$ and cotton ${ }^{51}$ biomass. However, the key difference between the heteroatom-doped activated carbon materials listed in Table 2 and our ELAC is that the former adopted an extraneous source (or precursor) for their heteroatom, adding considerable cost and time to the procedure, whereas ours derived its $\mathrm{N}, \mathrm{S}$-doped heteroatom directly from the biomass material (i.e., they are self-doped). The specific surface area of ELAC is higher compared to that of previously reported paulownia flower-based carbon materials. ${ }^{55}$ The abundant micropores improve electrolyte contact and enhance the electrochemical performance. The sulfur functional groups also increase wettability and electrical conductivity and, 
consequently, the electrochemical performance. Accordingly, we successfully prepared self-doped activated carbon material with a maximum specific capacitance of $216 \mathrm{~F} \mathrm{~g}^{-1}$ at $20 \mathrm{~A} \mathrm{~g}^{-1}$. Moreover, the ELAC also exhibited a relatively high specific surface area with capacitance comparable to the highest values reported in other studies. The main factors for a satisfactory specific capacitance in electrode include high specific surface area and the N/S surface functional groups.

A two-electrode symmetric capacitor was assembled with N,S-ELAC-2, the best-performing electrode in the study. This was tested in $6 \mathrm{M} \mathrm{KOH}$ electrolyte with a maximum mass loading of $10 \mathrm{mg}$. The symmetric capacitor performance at different voltages and a fixed scan rate of $50 \mathrm{mV} \mathrm{s}^{-1}$ is shown in Figure 6a. At $1.2 \mathrm{~V}$, the rectangular shape of the $\mathrm{CV}$ curve persisted, demonstrating that the symmetric capacitor can be reversibly cycled within the voltage window of $0-1.2 \mathrm{~V}$. The GCD curves of the symmetric capacitor at different current densities of $0.5-10 \mathrm{~A} \mathrm{~g}^{-1}$ (Figure 6b) show that their good linearity and symmetrical triangular shape were retained. The specific capacitance values, calculated using eq 1 (Figure 6c), achieved up to $84 \mathrm{~F} \mathrm{~g}^{-1}$ at a current density of $0.5 \mathrm{~A} \mathrm{~g}^{-1}$ for the entire electrode. Moreover, at $10 \mathrm{~A} \mathrm{~g}^{-1}$, the maximum capacitance was $62 \mathrm{~F} \mathrm{~g}^{-1}$. The average power density of the symmetric capacitor increased from 600 to $12000 \mathrm{~W} \mathrm{~kg}^{-1}$ with the current density (Figure $6 \mathrm{~d}$ ). The energy density of the symmetric capacitor remains at $12.4 \mathrm{Wh} \mathrm{kg}^{-1}$ at a power density of $12000 \mathrm{~W} \mathrm{~kg}$, higher than that of previously reported carbon symmetric supercapacitors in aqueous electrolyte, such as glucose-based porous carbon $\left(7.01 \mathrm{Wh} \mathrm{kg}^{-1}\right.$ at $\left.7200 \mathrm{~W} \mathrm{~kg}{ }^{-1}\right),{ }^{56}$ mesoporous carbon nanospheres $(9.1 \mathrm{Wh}$ $\mathrm{kg}^{-1}$ at $\left.3200 \mathrm{~W} \mathrm{~kg}^{-1}\right),{ }^{57}$ and chemical-modified graphene (5.2 $\mathrm{Wh} \mathrm{kg}{ }^{-1}$ at $\left.4000 \mathrm{~W} \mathrm{~kg}^{-1}\right){ }^{58}$ After 5000 cycles, the capacitance retention of the as-prepared symmetric capacitor was $87.2 \%$, suggesting excellent long-term cycling stability (Figure 6e,f). The cycling durability of the symmetric supercapacitor was confirmed by the GCD curves after 5000 cycles in Figure 6d. Observably, the curves were nearly symmetric, resembling that from previous cycle. These findings demonstrate that nitrogen and sulfur co-doped carbon derived from elm flower is a good material for applications in energy conversion and storage devices. The electrochemical results revealed that ELAC material is viable as a high-performance supercapacitor electrode.

\section{CONCLUSIONS}

A novel N,S-doped activated carbon has been successfully fabricated from elm flowers via a facile prehydrothermal reaction and $\mathrm{KOH}$ activation for supercapacitors. Through adjusting the mass ratio of $\mathrm{KOH}$ to the prehydrothermal carbonized elm flowers, the resultant N,S-doped activated carbon possesses a high specific surface area, moderate pore volume, and abundant functional groups. And the assynthesized N,S-doped activated carbon electrodes exhibited a high specific capacitance $\left(275 \mathrm{~F} \mathrm{~g}^{-1}\right.$ at $1 \mathrm{~A} \mathrm{~g}^{-1}$ and $216 \mathrm{~F} \mathrm{~g}^{-1}$ at $\left.20 \mathrm{~A} \mathrm{~g}^{-1}\right)$. In addition, the assembled symmetric supercapacitors based on this material demonstrated an energy density of $16.8 \mathrm{Wh} \mathrm{kg}^{-1}$ and power density of $600 \mathrm{~W} \mathrm{Kg}^{-1}$, as well as a stable cycle life over 5000 at $4 \mathrm{~A} \mathrm{~g}^{-1}$. These high performances demonstrate that the $\mathrm{N}, \mathrm{S}$-doped activated carbon derived from elm flowers is a good potential material in energy conversion and storage devices.

\section{EXPERIMENTAL SECTION}

4.1. Sample Preparation. Elm flowers were collected from Shihezi University (China, Xinjiang Province) in April. To remove impurities, elm flowers were repeatedly washed with deionized water. The samples were dried at $100{ }^{\circ} \mathrm{C}$ for $12 \mathrm{~h}$, and the flowers were crushed into powder subsequently. Powdered elm flowers of $2 \mathrm{~g}$ were added to $2.5 \mathrm{~mL}$ of concentrated sulfuric acid and $50 \mathrm{~mL}$ of deionized water in a $100 \mathrm{~mL}$ stainless-steel autoclave. The hydrothermal reaction occurred at $180^{\circ} \mathrm{C}$ for $48 \mathrm{~h}$. Thereafter, the mixture was cooled at room temperature and atmospheric pressure, was filtered, washed with deionized water, and then dried at $80{ }^{\circ} \mathrm{C}$ for $12 \mathrm{~h}$. The resulting hydrothermally treated sample (HEL) was thoroughly mixed with $\mathrm{KOH}$ in separate agate mortars at mass ratios of $1: 1,1: 2$, and $1: 3$. They were preactivated at 400 ${ }^{\circ} \mathrm{C}$ for $30 \mathrm{~min}$ and then heated to $700{ }^{\circ} \mathrm{C}$ for an additional $1 \mathrm{~h}$ under an Ar atmosphere in a tube furnace. The activated products were then washed with $10 \% \mathrm{v} / \mathrm{v} \mathrm{HCl}$ and deionized water and dried at $80{ }^{\circ} \mathrm{C}$ for $12 \mathrm{~h}$. Finally, the activated carbon samples, containing both nitrogen and sulfur, were accordingly labeled N,S-ELAC- $x$, where $x$ represents the mass ratio between $\mathrm{KOH}$ and HEL in the corresponding sample.

4.2. Material Characterization. X-ray diffraction (XRD) analysis was performed using a Bruker D8 Advance X-ray diffractometer with $\mathrm{Cu} \mathrm{K} \alpha$ radiation. The specific surface areas were calculated according to the Brunauer-Emmett-Teller (BET) method. The pore size distribution (PSD) of the samples was obtained from density functional theory method. The surface morphologies and microstructures of the samples were observed by scanning electron microscopy (SEM, SU8010) and transmission electron microscopy (TEM, Tecnai G2 F20). Trace elements were analyzed by energy-dispersive Xray mapping using an ISIS-300 spectrometer. X-ray photoelectron spectroscopy (XPS) was performed on an ESCALAB 250Xi (Thermo Fisher Scientific) spectrometer using monochromatic $\mathrm{Al} \mathrm{K} \alpha$ radiation $(h=1486.6 \mathrm{eV})$ with $210 \mathrm{~W}$. Raman characterization was conducted on a Horiba Jobin Yvon LabRAM HR800 Raman spectrometer.

4.3. Electrochemical Measurements. N,S-ELAC- $x$ (5.0 $\mathrm{mg})$ and poly(tetrafluoroethylene) solution $(1.0 \mu \mathrm{L}, 60 \mathrm{wt} \%$; Aladdin) were added to $1.0 \mathrm{~mL}$ of ethanol. The corresponding suspension was sonicated for at least $30 \mathrm{~min}$ until homogenization. This was then transferred into a rectangular $\mathrm{Ni}$ foam current collector $(1 \mathrm{~cm} \times 1 \mathrm{~cm})$ and vacuum dried at $80{ }^{\circ} \mathrm{C}$ for $12 \mathrm{~h}$. The electrochemical performance of the asprepared electrode material was tested using a three-electrode system in $6 \mathrm{M} \mathrm{KOH}$ electrolyte on an electrochemical workstation (CHI 760E, Shanghai). A platinum sheet and saturated calomel electrode served as counter and reference electrodes, respectively. Cyclic voltammetry (CV) and galvanostatic charge-discharge (GCD) measurements were performed over a potential window of -1 to $-0.1 \mathrm{~V}$ at different scan rates and current densities. Finally, the specific capacitances of the as-prepared materials were calculated from the GCD data by eq $1^{31,32}$

$$
C=I \Delta t / m \Delta V
$$

where $C\left(\mathrm{~F} \mathrm{~g}^{-1}\right)$ is the specific capacitance, $I(\mathrm{~A})$ is the charge/ discharge current, $\Delta t(\mathrm{~s})$ is the discharge time, $m(\mathrm{mg})$ is the mass of the active material in the electrode, and $\Delta V$ is the potential window.

The electrochemical performance of the two-electrode system was evaluated by assembling a symmetrical super- 
capacitor based on N,S-ELAC-2, with electrodes prepared as previous. N,S-ELAC-2 (5 mg) and a poly(tetrafluoroethylene) solution $(1.0 \mu \mathrm{L}, 60 \mathrm{wt} \%$, Aladdin) were added to $1.0 \mathrm{~mL}$ of ethanol and then sonicated until homogenization. The solution was then coated onto circular $\mathrm{Ni}$ foam current collectors $(0.785$ $\mathrm{cm}^{2}$ ) and vacuum dried at $80{ }^{\circ} \mathrm{C}$ for $12 \mathrm{~h}$. The dried electrodes were symmetrically assembled with cellulose membrane as the separator and $6 \mathrm{M} \mathrm{KOH}$ as the electrolyte in a CR2032 stainless-steel coin cell. CV and GCD analyses were conducted to evaluate the electrode performance.

$$
C_{\mathrm{t}}=2 I \Delta t / m \Delta V
$$

where $m(\mathrm{mg})$ is the total mass of the electrode, $I(\mathrm{~A})$ is the charge/discharge current, $\Delta t(\mathrm{~s})$ is the discharge time, $m(\mathrm{mg})$ is the mass of the active material in the electrode, and $\Delta V$ is the potential window.

$$
\begin{aligned}
& E=C(\Delta V)^{2} /(8 \times 3.6) \\
& P=(E \times 3600) / t
\end{aligned}
$$

where $E\left(\mathrm{Wh} \mathrm{kg}^{-1}\right)$ is the specific energy density, $P\left(\mathrm{~W} \mathrm{~kg}^{-1}\right)$ is the specific power density of the symmetrical supercapacitor system, $C\left(\mathrm{~F} \mathrm{~g}^{-1}\right)$ is the specific capacitance of the total symmetrical system, and $\Delta V$ is the potential window of discharge.

\section{ASSOCIATED CONTENT}

\section{S Supporting Information}

The Supporting Information is available free of charge on the ACS Publications website at DOI: 10.1021/acsomega.8b00210.

XRD spectra, nitrogen adsorption and desorption patterns together with pore size distribution, and SEM image of HEL; the columbic efficiency images of asprepared N,S-ELAC- $x$ (PDF)

\section{AUTHOR INFORMATION}

\section{Corresponding Authors}

*E-mail: yufeng05@mail.ipc.ac.cn (F.Y.).

*E-mail: pengshl@lzu.edu.cn. Tel: +86-993-205-7272. Fax: +86-993-05-7270 (S.P.).

ORCID

Feng Yu: 0000-0002-8140-8344

Bin Dai: 0000-0001-9254-6606

\section{Notes}

The authors declare no competing financial interest.

\section{ACKNOWLEDGMENTS}

This work was supported by the National Natural Science Foundation of China (Grant No. U1303291), the Program for Changjiang Scholars and Innovative Research Team in University (Grant No. IRT 15R46), and the Program of Science and Technology Innovation Team in Bingtuan (Grant No. 2015BD003).

\section{REFERENCES}

(1) Simon, P.; Gogotsi, Y. Materials for electrochemical capacitors. Nat. Mater. 2008, 7, 845-854.

(2) Zhang, J.; Zhao, X. On the configuration of supercapacitors for maximizing electrochemical performance. ChemSusChem 2012, 5, $818-841$.

(3) Zhang, L. L.; Zhao, X. Carbon-based materials as supercapacitor electrodes. Chem. Soc. Rev. 2009, 38, 2520-2531.
(4) Stoller, M. D.; Ruoff, R. S. Best practice methods for determining an electrode material's performance for ultracapacitors. Energy Environ. Sci. 2010, 3, 1294-1301.

(5) Hao, L.; Li, X.; Zhi, L. Carbonaceous electrode materials for supercapacitors. Adv. Mater. 2013, 25, 3899-3904.

(6) Mao, N.; Wang, H.; Sui, Y.; Cui, Y.; Pokrzywinski, J.; Shi, J.; Liu, W.; Chen, S.; Wang, X.; Mitlin, D. Extremely high-rate aqueous supercapacitor fabricated using doped carbon nanoflakes with large surface area and mesopores at near-commercial mass loading. Nano Res. 2017, 10, 1767-1783.

(7) Zhu, B.; Liu, B.; Qu, C.; Zhang, H.; Guo, W.; Liang, Z.; Chen, F.; Zou, R. Tailoring biomass-derived carbon for high-performance supercapacitors from controllably cultivated algae microspheres. $J$. Mater. Chem. A 2018, 6, 1523-1530.

(8) Shi, C.; Hu, L.; Guo, K.; Li, H.; Zhai, T. Highly porous carbon with graphene nanoplatelet microstructure derived from biomass waste for high-performance supercapacitors in universal electrolyte. Adv. Sustainable Syst. 2017, 1, No. 1600011.

(9) Han, S.; Wu, D.; Li, S.; Zhang, F.; Feng, X. Porous graphene materials for advanced electrochemical energy storage and conversion devices. Adv. Mater. 2014, 26, 849-864.

(10) Jeong, H. M.; Lee, J. W.; Shin, W. H.; Choi, Y. J.; Shin, H. J.; Kang, J. K.; Choi, J. W. Nitrogen-doped graphene for highperformance ultracapacitors and the importance of nitrogen-doped sites at basal planes. Nano Lett. 2011, 11, 2472-2477.

(11) Chen, L. F.; Lu, Y.; Yu, L.; Lou, X. W. Designed formation of hollow particle-based nitrogen-doped carbon nanofibers for highperformance supercapacitors. Energy Environ. Sci. 2017, 10, 17771783.

(12) Yan, J.; Wang, Q.; Wei, T.; Fan, Z. Recent advances in design and fabrication of electrochemical supercapacitors with high energy densities. Adv. Energy Mater. 2014, 4, No. 1300816.

(13) Wang, Y.; Xuan, H.; Lin, G.; Wang, F.; Chen, Z.; Dong, X. A melamine-assisted chemical blowing synthesis of $\mathrm{N}$-doped activated carbon sheets for supercapacitor application. J. Power Sources 2016, 319, 262-270.

(14) Ma, G.; Yang, Q.; Sun, K.; Peng, H.; Ran, F.; Zhao, X.; Lei, Z. Nitrogen-doped porous carbon derived from biomass waste for highperformance supercapacitor. Bioresour. Technol. 2015, 197, 137-142.

(15) Sun, F.; Gao, J.; Pi, X.; Wang, L.; Yang, Y.; Qu, Z.; Wu, S. High performance aqueous supercapacitor based on highly nitrogen-doped carbon nanospheres with unimodal mesoporosity. J. Power Sources 2017, 337, 189-196.

(16) Su, F.; Poh, C. K.; Chen, J. S.; Xu, G.; Wang, D.; Li, Q.; Lin, J.; Lou, X. W. Nitrogen-containing microporous carbon nanospheres with improved capacitive properties. Energy Environ. Sci. 2011, 4, 717-724.

(17) Chen, X. Y.; Chen, C.; Zhang, Z. J.; Xie, D. H.; Deng, X.; Liu, J. W. Nitrogen-doped porous carbon for supercapacitor with long-term electrochemical stability. J. Power Sources 2013, 230, 50-58.

(18) Tian, W.; Zhang, H.; Sun, H.; Tadé, M. O.; Wang, S. Templatefree synthesis of $\mathrm{N}$-doped carbon with pillared-layered pores as bifunctional materials for supercapacitor and environmental applications. Carbon 2017, 118, 98-105.

(19) Li, B.; Dai, F.; Xiao, Q.; Yang, L.; Shen, J.; Zhang, C.; Cai, M. Nitrogen-doped activated carbon for a high energy hybrid supercapacitor. Energy Environ. Sci. 2016, 9, 102-106.

(20) Zhang, W.; Xu, C.; Ma, C.; Li, G.; Wang, Y.; Zhang, K.; Li, F.; Liu, C.; Cheng, H. M.; Du, Y. Nitrogen-superdoped 3D graphene networks for high-performance supercapacitors. Adv. Mater. 2017, 29, $1-9$.

(21) Liu, S.; Cai, Y.; Zhao, X.; Liang, Y.; Zheng, M.; Hu, H.; Dong, H.; Jiang, S.; Liu, Y.; Xiao, Y. Sulfur-doped nanoporous carbon spheres with ultrahigh specific surface area and high electrochemical activity for supercapacitor. J. Power Sources 2017, 360, 373-382.

(22) Islam, M. M.; Subramaniyam, C. M.; Akhter, T.; Faisal, S. N.; Minett, A. I.; Liu, H. K.; Konstantinov, K.; Dou, S. X. Three dimensional cellular architecture of sulfur doped graphene: selfstanding electrode for flexible supercapacitors, lithium ion and sodium ion batteries. J. Mater. Chem. A 2017, 5, 5290-5302. 
(23) Ji, H.; Wang, T.; Liu, Y.; Lu, C.; Yang, G.; Ding, W.; Hou, W. Novel approach for sulfur-doped hierarchically porous carbon with excellent capacitance for electrochemical energy storage. Chem. Commun. 2016, 52, 12725-12728.

(24) Huang, Y.; Candelaria, S. L.; Li, Y.; Li, Z.; Tian, J.; Zhang, L.; Cao, G. Sulfurized activated carbon for high energy density supercapacitors. J. Power Sources 2014, 252, 90-97.

(25) Zhang, D.; Han, M.; Wang, B.; Li, Y.; Lei, L.; Wang, K.; Wang, Y.; Zhang, L.; Feng, H. Superior supercapacitors based on nitrogen and sulfur co-doped hierarchical porous carbon: Excellent rate capability and cycle stability. J. Power Sources 2017, 358, 112-120.

(26) Kotal, M.; Kim, H.; Roy, S.; Oh, I. K. Sulfur and nitrogen codoped holey graphene aerogel for structurally resilient solid-state supercapacitors under high compressions. J. Mater. Chem. A 2017, 5, 17253-17266.

(27) Li, Y.; Wang, G.; Wei, T.; Fan, Z.; Yan, P. Nitrogen and sulfur co-doped porous carbon nanosheets derived from willow catkin for supercapacitors. Nano Energy 2016, 19, 165-175.

(28) Hasegawa, G. Studies on Porous Monolithic Materials Prepared via Sol-Gel Processes; Springer: Japan, 2012; pp 208-213.

(29) Zhao, X.; Zhang, Q.; Chen, C. M.; Zhang, B.; Reiche, S.; Wang, A.; Zhang, T.; Schlögl, R.; Su, D. S. Aromatic sulfide, sulfoxide, and sulfone mediated mesoporous carbon monolith for use in supercapacitor. Nano Energy 2012, 1, 624-630.

(30) Chen, C.; Yu, D.; Zhao, G.; Du, B.; Tang, W.; Sun, L.; Sun, Y.; Besenbacher, F.; Yu, M. Three-dimensional scaffolding framework of porous carbon nanosheets derived from plant wastes for highperformance supercapacitors. Nano Energy 2016, 27, 377-389.

(31) Laheäär, A.; Przygocki, P.; Abbas, Q.; Béguin, F. Appropriate methods for evaluating the efficiency and capacitive behavior of different types of supercapacitors. Electrochem. Commun. 2015, 60, $21-25$.

(32) Chen, L.-F.; Zhang, X.-D.; Liang, H.-W.; Kong, M.; Guan, Q.-F.; Chen, P.; Wu, Z.-Y.; Yu, S.-H. Synthesis of nitrogen-doped porous carbon nanofibers as an efficient electrode material for supercapacitors. ACS Nano 2012, 6, 7092-7102.

(33) Wang, H.; Xu, Z.; Kohandehghan, A.; Li, Z.; Cui, K.; Tan, X.; Stephenson, T. J.; King'ondu, C. K.; Holt, C. M.; Olsen, B. C.; et al. Interconnected carbon nanosheets derived from hemp for ultrafast supercapacitors with high energy. ACS Nano 2013, 7, 5131-5141.

(34) Ding, J.; Wang, H.; Li, Z.; Cui, K.; Karpuzov, D.; Tan, X.; Kohandehghan, A.; Mitlin, D. Peanut shell hybrid sodium ion capacitor with extreme energy-power rivals lithium ion capacitors. Energy Environ. Sci. 2015, 8, 941-955.

(35) Liu, H.; Wang, K.; Teng, H. A simplified preparation of mesoporous carbon and the examination of the carbon accessibility for electric double layer formation. Carbon 2005, 43, 559-566.

(36) McEvoy, N.; Peltekis, N.; Kumar, S.; Rezvani, E.; Nolan, H.; Keeley, G. P.; Blau, W. J.; Duesberg, G. S. Synthesis and analysis of thin conducting pyrolytic carbon films. Carbon 2012, 50, 1216-1226.

(37) Figueiredo, J.; Rivera-Utrilla, J.; Ferro-Garcia, M. Gasification of active carbons of different texture impregnated with nickel, cobalt and iron. Carbon 1987, 25, 703-708.

(38) Qie, L.; Chen, W.; Xu, H.; Xiong, X.; Jiang, Y.; Zou, F.; Hu, X.; Xin, Y.; Zhang, Z.; Huang, Y. Synthesis of functionalized 3D hierarchical porous carbon for high-performance supercapacitors. Energy Environ. Sci. 2013, 6, 2497-2504.

(39) Wang, C.; Wang, Y.; Graser, J.; Zhao, R.; Gao, F.; O'Connell, M. J. Solution-based carbohydrate synthesis of individual solid, hollow, and porous carbon nanospheres using spray pyrolysis. ACS Nano 2013, 7, 11156-11165.

(40) Qian, W.; Zhu, J.; Zhang, Y.; Wu, X.; Yan, F. Condimentderived 3D architecture porous carbon for electrochemical supercapacitors. Small 2015, 11, 4959-4969.

(41) Zhu, Y.; Murali, S.; Stoller, M. D.; Ganesh, K.; Cai, W.; Ferreira, P. J.; Pirkle, A.; Wallace, R. M.; Cychosz, K. A.; Thommes, M.; et al. Carbon-based supercapacitors produced by activation of graphene. Science 2011, 332, 1537-1541.
(42) Xie, L.; Sun, G.; Su, F.; Guo, X.; Kong, Q.; Li, X.; Huang, X.; Wan, L.; Li, K.; Lv, C.; et al. Hierarchical porous carbon microtubes derived from willow catkins for supercapacitor applications. J. Mater. Chem. A 2016, 4, 1637-1646.

(43) Sadezky, A.; Muckenhuber, H.; Grothe, H.; Niessner, R.; Pöschl, U. Raman microspectroscopy of soot and related carbonaceous materials: spectral analysis and structural information. Carbon 2005, 43, 1731-1742.

(44) Li, M.; Liu, C.; Cao, H.; Zhao, H.; Zhang, Y.; Fan, Z. KOH selftemplating synthesis of three-dimensional hierarchical porous carbon materials for high performance supercapacitors. J. Mater. Chem. A 2014, 2, 14844-14851.

(45) Kim, N. D.; Buchholz, D. B.; Casillas, G.; José-Yacaman, M.; Chang, R. P. Hierarchical design for fabricating cost-effective high performance supercapacitors. Adv. Funct. Mater. 2014, 24, 4186-4194.

(46) Glenis, S.; Nelson, A.; Labes, M. Sulfur doped graphite prepared via arc discharge of carbon rods in the presence of thiophenes. J. Appl. Phys. 1999, 86, 4464-4466.

(47) Wang, C.; Zhou, Y.; Sun, L.; Wan, P.; Zhang, X.; Qiu, J. Sustainable synthesis of phosphorus-and nitrogen-co-doped porous carbons with tunable surface properties for supercapacitors. J. Power Sources 2013, 239, 81-88.

(48) Yun, Y. S.; Cho, S. Y.; Shim, J.; Kim, B. H.; Chang, S. J.; Baek, S. J.; Huh, Y. S.; Tak, Y.; Park, Y. W.; Park, S.; et al. Microporous carbon nanoplates from regenerated silk proteins for supercapacitors. $A d v$. Mater. 2013, 25, 1993-1998.

(49) Chen, H.; Liu, D.; Shen, Z.; Bao, B.; Zhao, S.; Wu, L. Functional biomass carbons with hierarchical porous structure for supercapacitor electrode materials. Electrochim. Acta 2015, 180, 241-251.

(50) Liu, B.; Zhang, L.; Qi, P.; Zhu, M.; Wang, G.; Ma, Y.; Guo, X.; Chen, H.; Zhang, B.; Zhao, Z.; et al. Nitrogen-doped banana peelderived porous carbon foam as binder-free electrode for supercapacitors. Nanomaterials 2016, 6, No. 18.

(51) Chen, L.; Ji, T.; Mu, L.; Zhu, J. Cotton fabric derived hierarchically porous carbon and nitrogen doping for sustainable capacitor electrode. Carbon 2017, 111, 839-848.

(52) Xu, D.; Hu, W.; Sun, X. N.; Cui, P.; Chen, X. Y. Redox additives of $\mathrm{Na}_{2} \mathrm{MoO}_{4}$ and $\mathrm{KI}$ : Synergistic effect and the improved capacitive performances for carbon-based supercapacitors. J. Power Sources 2017, $341,448-456$.

(53) Nie, Y.; Wang, Q.; Chen, X.; Zhang, Z. Nitrogen and oxygen functionalized hollow carbon materials: the capacitive enhancement by simply incorporating novel redox additives into $\mathrm{H}_{2} \mathrm{SO}_{4}$ electrolyte. $J$. Power Sources 2016, 320, 140-152.

(54) Zhang, Z. J.; Zheng, Q. C.; Sun, L.; Xu, D.; Chen, X. Twodimensional carbon nanosheets for high-performance supercapacitors: large-scale synthesis and codoping with nitrogen and phosphorus. Ind. Eng. Chem. Res. 2017, 56, 12344-12353.

(55) Chang, J.; Gao, Z.; Wang, X.; Wu, D.; Xu, F.; Wang, X.; Guo, Y.; Jiang, $\mathrm{K}$. Activated porous carbon prepared from paulownia flower for high performance supercapacitor electrodes. Electrochim. Acta 2015, 157, 290-298.

(56) Chang, C.; Yang, X.; Xiang, S.; Lin, X.; Que, H.; Li, M. Nitrogen and Sulfur Co-Doped Glucose-Based Porous Carbon Materials with Excellent Electrochemical Performance for Supercapacitors. J. Electrochem. Soc. 2017, 164, A1601-A1607.

(57) Lei, Z.; Christov, N.; Zhang, L. L.; Zhao, X. S. Mesoporous carbon nanospheres with an excellent electrocapacitive performance. J. Mater. Chem. 2011, 21, 2274-2281.

(58) Choi, B. G.; Yang, M.; Hong, W. H.; Choi, J. W.; Huh, Y. S. 3D macroporous graphene frameworks for supercapacitors with high energy and power densities. ACS Nano 2012, 6, 4020-4028. 